\title{
Hilando entre las rocas... análisis de los diseños de torteros foráneos en el arte rupestre de Cerro Colorado (norte de Córdoba, Argentina)
}

\section{Spinning among the rocks ... analysis of the designs of foreign spindle whorls in Cerro Colorado rock art (north of Córdoba, Argentina)}

\author{
Andrea Recalde ${ }^{1}$
}

\begin{abstract}
Resumen
Se analizan algunos rasgos del arte rupestre de la localidad arqueológica de Cerro Colorado (Sierras del Norte, Córdoba), en el marco de un repertorio dominado por elementos compartidos. El examen de estos diseños y su comparación con referentes iconográficos locales y extrarregionales proporcionan argumentos para comprender sus incorporaciones y, junto con esto, proponer líneas que permitan indagar respecto a los procesos sociales que tuvieron lugar en la región durante el período Prehispánico Tardío (400-1550 DC). Algunos motivos de Cerro Colorado aluden a los diseños de los torteros hallados en la región media del río Salado (Santiago del Estero), pero también en el sitio La Paya (valle Calchaquí). Su inclusión en un contexto histórico local marcado por tensiones sociales que involucraban a diferentes esferas de interacción indica que estos motivos, probablemente resignificados respecto a su sentido social original, constituyeron recursos simbólicos activos en el fortalecimiento y demarcación hacia adentro y hacia fuera del grupo que participaba en la observación y ejecución del arte, a partir de los vínculos establecidos con poblaciones asentadas en otras regiones.
\end{abstract}

Palabras claves: arte rupestre, identidad, torteros, período Prehispánico Tardío, norte de Córdoba.

\begin{abstract}
This paper analysis some rock art motifs that breaking with a Cerro Colorado (Sierras del Norte, Córdoba) shared repertoire. The local and macro regional iconographic comparison provide us guidelines for understanding their incorporation into the local repertoire. In the same way, this comparative strategy allow to proposed lines to inquiry about the social processes that took place in the region during the Late Pre-hispanic period (400-1550 AD). Thus, some motifs of Cerro Colorado are similar to the designs of the spindle whorls found in the middle region of Salado river (Santiago del Estero) but also on site of La Paya (Calchaqui Valley). Its inclusion in a local historical context marked by social tensions involving different spheres of interaction indicates that these designs were symbolic resources to strengthen and demarcation within and also out of the group from the reference to the ties established with communities, for example, of the of the lowlands of Santiago del Estero.
\end{abstract}

Keywords: rock art, identity, spindle whorls, Late Pre-hispanic period, North of Córdoba.

Recibido: 28 mayo 2016. Aceptado: 10 marzo 2017

1 CONICET. Área de Arqueología del IEH/CEH "Prof. Carlos S.A. Segreti”.

Universidad Nacional de Córdoba, Córdoba, ARGENTINA. Email: recaldema@yahoo.com.ar 


\section{Introducción}

La localidad de Cerro Colorado, emplazada al norte de la actual provincia de Córdoba (centro de Argentina), es considerada en el marco de la arqueología regional como un paisaje rupestre, es decir, como un entorno en el cual el arte gravitaba en las prácticas sociales que allí tenían lugar. La construcción de este paisaje se desarrolló fundamentalmente durante el período Prehispánico Tardío (PPT) (ca. 400-1550 DC), momento a partir del cual hay evidencias de incremento de tensiones sociales y políticas entre los grupos que ocuparon gran parte de la región cordobesa (Pastor et al., 2012; Díaz et al., 2015).

En este contexto, los 50 sitios con representaciones emplazados en Cerro Colorado fueron tanto el resultado como el medio para la construcción de espacios de negociación de identidades, entendidas éstas como toda instancia de autorreconocimiento y diferenciación con la alteridad (Hastorf, 2003; Díaz-Andreu, 2005; Jones, 2007). Los sitios con arte rupestre pueden ser así considerados como "lugares de identidad" (Augé, 1998, p. 57), en cuanto espacios que se construyen a lo largo del tiempo sobre la base de la referencia hacia un nosotros y donde las personas y/o grupos reconocen rasgos que aluden a sentidos de pertenencia específicos. Así, los lugares no conforman solo espacios de habitación donde solo tienen lugar las tareas cotidianas, sino que están definidos por y a partir de las actividades realizadas en ellos, es decir, a partir de la dialéctica entre personas y cosas. Esto implica que con el paso del tiempo y con la acción rutinaria y repetitiva de la praxis, estos lugares fueron imbuidos con memoria e identidad (Jones, 1998, p. 58; Pauketat, 2000, p. 48; Domingo Sanz et al., 2009).

Concomitante con esto, proponemos que la existencia en el arte rupestre de un repertorio común da cuenta de la circulación de un código simbólico que permite transmitir aquellos elementos idiosincráticos compartidos, los cuales refuerzan los sentimientos étnicos comunes forjados en la cotidianeidad de las prácticas (Lucy, 2005). Estas maneras de hacer e interpretar la realidad que los rodea apuntaban a la construcción de un marco de referencia más inclusivo que involucraba a todos los grupos que ocupaban el área de Cerro Colorado, e incluso que remarcaba los lazos y vínculos con comunidades ubicadas en otros sectores serranos cordobeses, como por ejemplo, el occidente de las Sierras Grandes. Por otra parte, la circulación de rasgos o diseńos poco frecuentes en el registro, entendidos como distribuciones no aleatorias de particulares maneras de hacer (Insoll, 2007, p. 53), aludían a la edificación de identidades hacia el interior de los grupos domésticos o unidades sociales reducidas, como expresiones mínimas de pertenencia definidas por los propios actores en el marco de circunstancias históricas específicas (Recalde, 2015a). Ambas expresiones, ambas narrativas construidas en torno a la rutina vinculada a la ejecución y observación del arte rupestre de los sitios no son excluyentes, dado que la presencia de elementos que no tienen un anclaje en el mundo social al cual se integran puede interpretarse como una manera de negociar y construir sentidos nuevos de pertenencia e identidad. Esto pone en evidencia no solo el proceso continuo y cambiante involucrado en la edificación de las prácticas identitarias, sino la posibilidad de que dentro del grupo o los grupos se construyan rangos de identidades diferentes, sin que la noción de comunidad sea negada (Lucy, 2005).

El objetivo de este trabajo es comprender el papel de algunas representaciones no figurativas que podemos interpretar como elementos "foráneos" dentro del repertorio que circula en la localidad arqueológica de Cerro Colorado, dado que tienen una baja frecuencia en los más de 100 paneles allí documentados. Nuestra propuesta, basada en un análisis iconográfico, partió de una búsqueda del repertorio presente en otros soportes del registro arqueológico de las Sierras Centrales (vasijas cerámicas, torteros, adornos, puntas de proyectil, entre otros). Fue la ausencia de resoluciones que autorizaran a trazar semejanzas lo que obligó a ampliar la búsqueda a nivel macrorregional, estrategia que permitió identificar similitudes con diseńos de torteros o muyunas de Santiago del Estero, e incluso con algunos ejemplares del valle Calchaquí. Esta procedencia posibilitó proponer líneas de análisis respecto a las implicancias sociales de su presencia en el contexto de tensiones y conflictos acaecidos en Sierras Centrales en momentos finales del período Prehispánico Tardío (ca. 1000-1550 DC). 


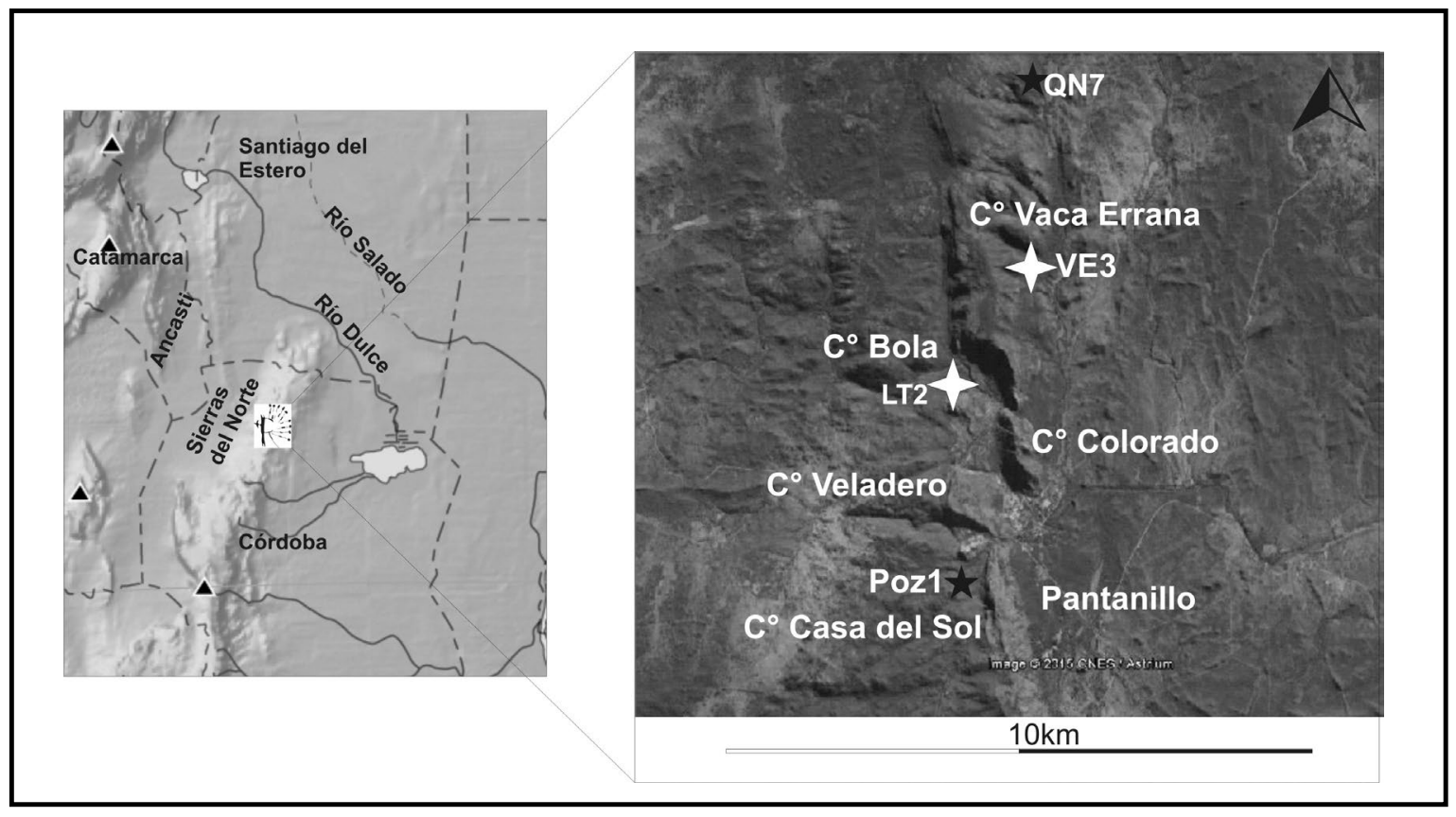

Figura 1. Mapa de la macrorregión y localización de los sitios mencionados en el texto para la localidad de Cerro Colorado.

\section{Contextos sociales o arte rupestre en contexto}

La localidad arqueológica de Cerro Colorado está ubicada en las Sierras del Norte, formación que se integra a las Sierras Centrales, la cual está emplazada en la región centro de Argentina. Este sistema de escasa altitud, con máximas que apenas superan los $1000 \mathrm{msnm}$, se prolongan en las denominadas Sierras de Ambargasta, las cuales comparte con la actual provincia de Santiago del Estero (Figura 1).

En las laderas de los cerros más significativos que integran esta localidad, como el Colorado, Veladero, Casa del Sol, Vaca Errana, se disponen 54 sitios identificados hasta el momento (Recalde, 2015a; Colqui, 2016). Las particularidades de los tipos de soportes seleccionados y su emplazamiento, fundamentalmente en los sectores medios de las formaciones, generan una condición de intervisibilidad (sensu Criado Boado, 1996) entre abrigos rocosos con representaciones. Al tiempo que también facilita una visualización desde los sitios hacia el paisaje circundante. Entre las quebradas transversales, asociadas al colector principal (río Los Tártagos) y a los arroyos serranos que desembocan en él (Los Molles,
Aguas de Figueroas o Pozancón, La Quebrada), hemos documentado ocupaciones al aire libre vinculadas con terrenos potencialmente cultivables y áreas de molienda de diversos tamaños (varían de 2 a 33 instrumentos fijos; Recalde, 2015a). ${ }^{2}$

Las escasas evidencias superficiales directamente asociadas al 55.5\% (N: 30) de los sitios con arte rupestre (instrumentos de molienda y fragmentos cerámicos) y el tipo y la baja densidad de restos recuperados en las tareas de excavación y sondeo efectuadas en seis sitios con arte rupestre permiten proponer que se trata de eventos ocupacionales realizados por un número reducido de individuos (Recalde, 2015a).

2 La ausencia de arquitectura de piedra en la región obliga a fijar parámetros metodológicos que permitan identificar las ocupaciones tipo residenciales o sitios multipropósitos al aire libre. En consecuencia, la concentración superficial de artefactos (líticos, cerámicos) y restos arqueofaunísticos, sumado a la asociación a terrenos potencialmente cultivables constituyen los indicadores utilizados para la identificación inicial de este tipo de ocupaciones. 
En las áreas aledañas a las formaciones documentamos cuatro ocupaciones multipropósito o poblados tardíos. Los datos analizados dan cuenta de la realización de prácticas de recolección, procesamiento y consumo de especies vegetales y animales (artefactos líticos, fragmentos cerámicos, instrumentos de hueso); también hemos recuperado e identificado macro y microrrestos botánicos que indican la realización de prácticas agrícolas prehispánicas en el área (maíz, poroto, papa, quinoa) (López y Recalde, 2016). Finalmente, relevamos 21 áreas de molienda, distribuidas en ambas márgenes del río y de los arroyos que surcan la zona y en abrigos rocosos ubicados en las laderas de las formaciones.

La conjunción de toda esta información, sumada a los fechados radiocarbónicos obtenidos en el área que abarcan un lapso entre $1250 \pm 80$ años AP (LP3212, carbón) (Recalde, 2015a) y 405 \pm 21 AP (AA 107245, grano de maíz) autorizan a definir que el paisaje de Cerro Colorado fue socialmente construido de manera constante y cotidiana, fundamentalmente durante el período Prehispánico Tardío (en adelante PPT) (400-1550 DC). El PPT se caracteriza, entre otros procesos, por el incremento de los mecanismos de integración política y cooperación entre grupos como estrategia fundamental frente a una instancia compleja de expansión de las sociedades indígenas. Estos cambios, cuyas raíces se remontan al 2000 AP (Rivero, 2009; Recalde, 2015b), se materializan en un crecimiento demográfico paulatino (aumento significativo del número de sitios), en estrategias de intensificación y diversificación de las prácticas económicas y en la incorporación a los circuitos de movilidad de ambientes chaqueños hasta entonces marginales. Paralelamente estos cambios crecientes van acompańados de un incremento del conflicto social, generado por la mayor competencia y tensión tanto entre como al interior de las unidades sociales, con diversos grados de inclusión (comunidades, familias extensas) (Pastor et al., 2012). En este sentido, las líneas que indican un escenario de tensión y violencia provienen de diferentes fuentes documentales, que señalan conflictos vinculados con la territorialidad o por diferencias entre comunidades políticamente autónomas (Berberián, 1984; Piana, 1992; Montes, 2008). También hay claros indicios de violencia en las evidencias osteológicas re- cuperadas en la región (González, 1940; Díaz et al., 2015) y, relacionado con esto, los cambios tecnológicos identificados en las puntas de proyectil, ya que las particularidades de sus diseños, generalizados a partir del 1000 AP, junto al uso del arco, indican su empleo fundamentalmente para el conflicto armado (Pastor et al., 2005; Rivero y Recalde, 2011). Finalmente, a estos datos se suman los testimonios simbólicos observados en algunas escenas del arte rupestre de Cerro Colorado que fueron interpretadas como de hostilidad y enfrentamientos (Gardner, 1931; González, 1977; Rivero y Recalde, 2011).

En este contexto de tensión y conflicto, que tuvo su máxima expresión en las Sierras Centrales en momentos finales del PPT (ca. 1200 a 1550 DC), es cuando la construcción de espacios de alianza y negociación constituyeron estrategias fundamentales para la continuidad de las comunidades (Pastor, 2007, 2012; Recalde, 2009). El arte rupestre, como práctica que integra un sistema simbólico, constituye una materialidad estructurante y estructuradora del mundo social en el cual las representaciones, y específicamente el repertorio compartido, constituyen los símbolos de integración social, en cuanto instrumentos de conocimiento y comunicación que intervinieron en la construcción de un marco idiosincrático compartido (Bourdieu, 1977). Esta materialidad constituyó así un espacio de negociación de la memoria y la identidad (Bauman, 2005; Kuit, 2008), dado que conjugaba expresiones conjuntas y comunitarias de reconocimiento al tiempo que articulaba los rasgos únicos que connotan las pertenencias mínimas (familiares e incluso individuales), ${ }^{3}$ sin entrar en contradicciones aparentes. Es por ello que las modificaciones en el repertorio del arte rupestre de Cerro Colorado, manifiestas en la incorporación de nuevos patrones de diseño de determinadas figuras geométricas, constituyen los rasgos que nos habilitan a indagar respecto a las razones sociales y políticas de estas incorporaciones.

3 En la mayoría de los paneles que integran la localidad de Cerro Colorado observamos escenas que constituyen miniaturas, dado que en algunos casos su longitud apenas superan los $5 \mathrm{~cm}$. Esta condición genera un vínculo directo entre la persona y los motivos, un diálogo directo entre agente y soporte, que podría estar reforzando su identidad. 


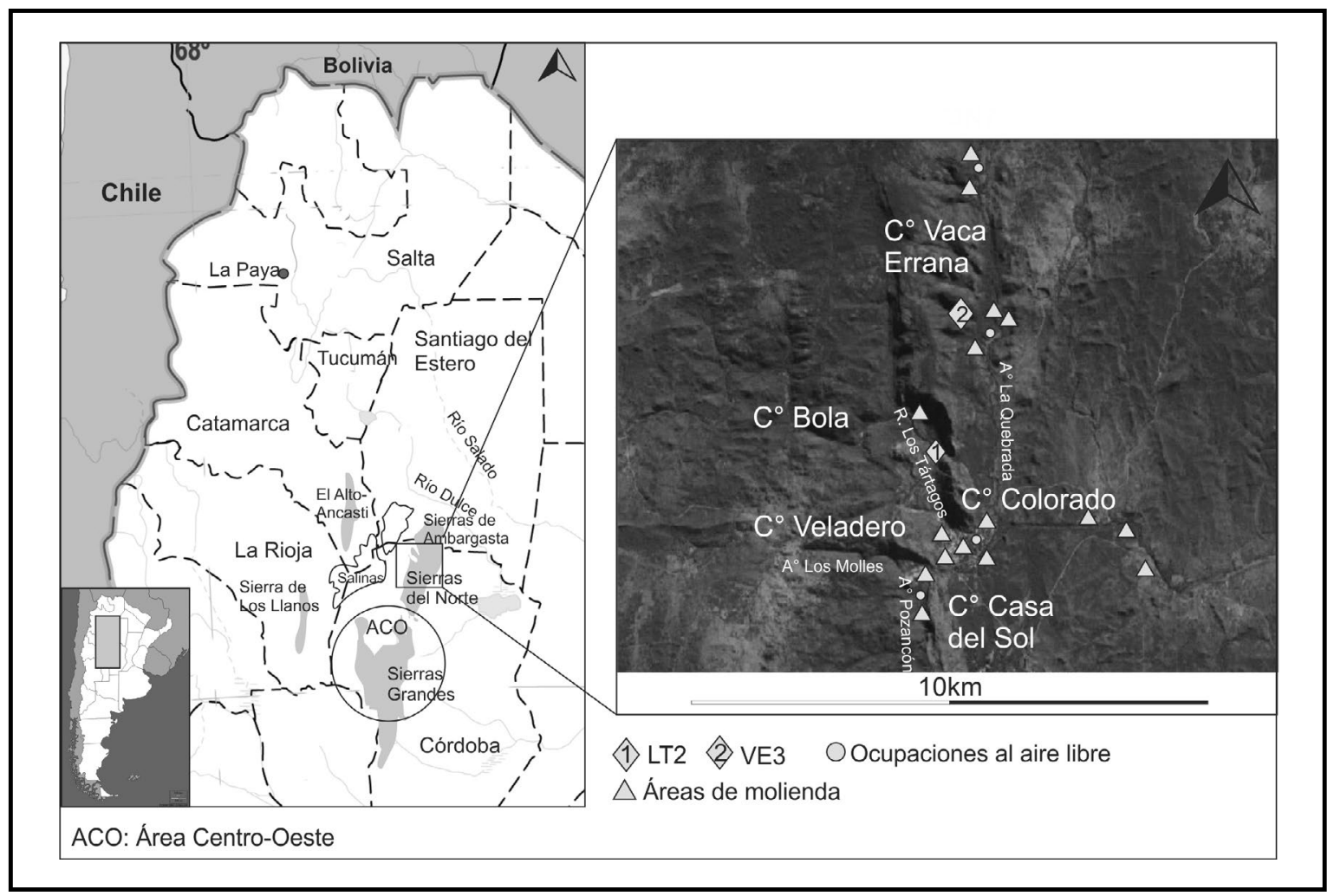

Figura 2. Distribución de los tipos de motivos entre las formaciones que integran la localidad.

\section{Particularidades del arte rupestre}

Como primer punto, resulta necesaria una caracterización del repertorio de la localidad a los fines de reforzar la singularidad de los diseños identificados como expresiones únicas, tanto en el área como en la región. El total de motivos presentes en Cerro Colorado es de 4220, divididos entre figurativos (62.49\%), no figurativos (35.78\%) e indefinidos $(1.73 \%){ }^{4}$ El primer grupo está, a su vez, subdividido sobre la base de un criterio claramente cronológico entre prehispánicos e hispánicos, agrupando en el marco de la segunda categoría todas las representaciones que nos permiten individualizar y caracterizar rasgos que fueron integrados al repertorio a partir de la Conquista (Recalde, 2015a; Recalde y González Navarro, 2015). Entre las representaciones prehispánicas individualizamos antropomorfos, zoomorfos, fitomorfos y objetos. Casi todos estos ti-

4 En este grupo se incluyen aquellos motivos que no pudimos vincular a un referente concreto debido al mal estado de conservación de la figura o el soporte. pos presentan una amplia distribución entre las formaciones que conforman la localidad arqueológica (Figura 2), lo cual denota una manera compartida de materializar el marco idiosincrático común a partir del cual se estructura el repertorio. No obstante, este primer acercamiento a partir de los tipos marcados por cierta homogeneidad en las definiciones, se desdibuja en el instante en que atendemos la gran variabilidad que presenta al interior de cada uno. Por lo tanto, un análisis fino permite comenzar a identificar las maneras particulares de plasmar cada una de estas representaciones.

El caso más claro resulta del análisis de uno de los motivos preponderantes entre los zoomorfos que, como ya lo destacaran otros investigadores (Gardner, 1931; Bolle, 1987), es el camélido. Esta es la figura dominante en el total de los animales identificados con un $84,56 \%$ (N: 1194); presenta una amplia distribución, puesto que fue relevado en 41 de los 54 sitios, y constituye la figura estructural de las asociaciones temáticas y las escenas. Lejos de 


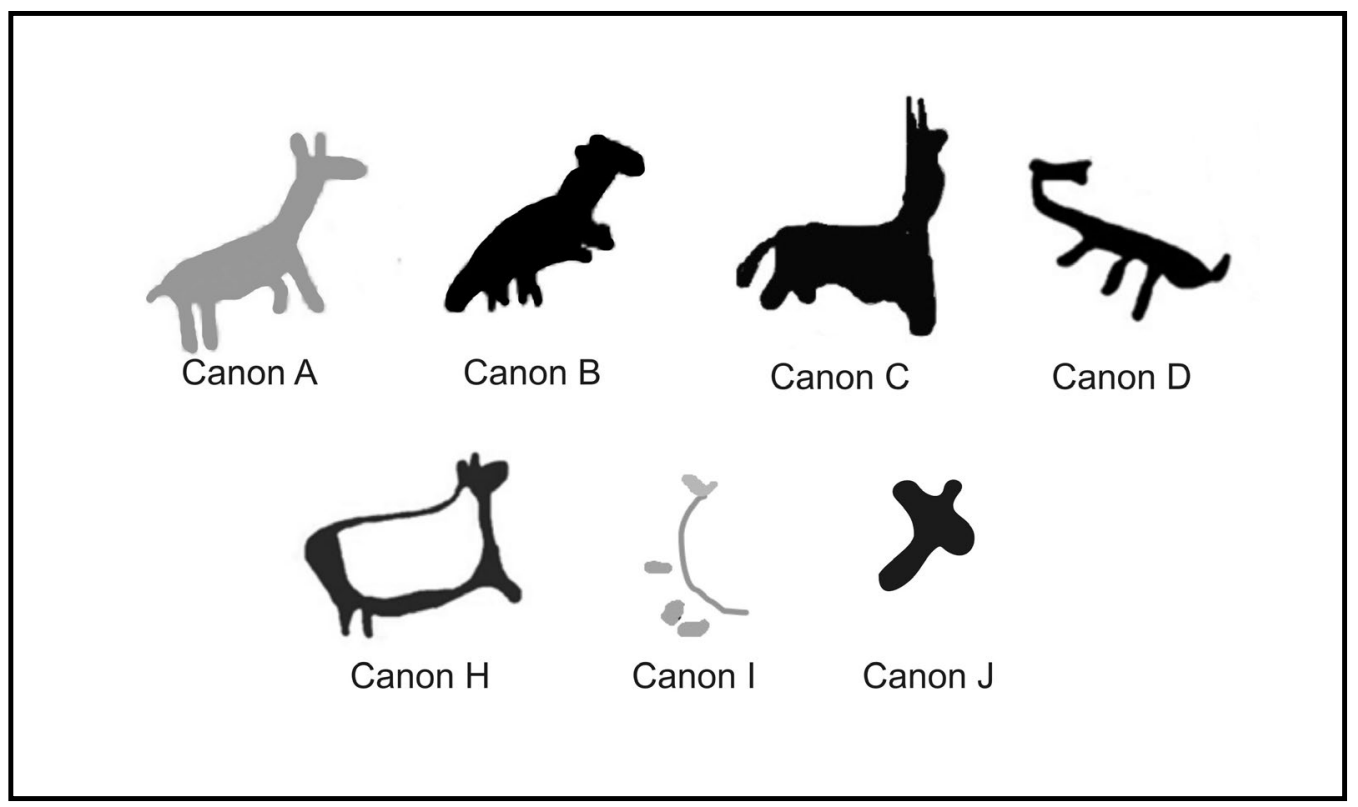

Figura 3. Cánones de camélidos identificados en la localidad de Cerro Colorado.

haber una resolución formal para su definición, hemos individualizado siete cánones (sensu Aschero, 1994), cuatro inicialmente identificados para el occidente de Córdoba (A, B, C, D) (Recalde, 2009; Recalde y Pastor, 2011) y tres que son específicos de la localidad (H, I y J). Llama la atención que hay un predominio del canon A con el 67,92\% (N: 811) por sobre las otras definiciones, aun las locales, lo cual lo convierte en un rasgo sensible a la hora de fijar vínculos con otras regiones de las Sierras Centrales (Figura 3).

El análisis de los motivos antropomorfos generó tradicionalmente gran interés entre los investigadores dada la particularidad de sus diseños (p.e., Serrano, 1945; González, 1977) y por estar distribuidos en todas las formaciones del área. La caracterización de la resolución formal de esta figura nos ha permitido individualizar cuatro cánones (Figura 4) (Recalde, 2015a), dos de los cuales -A y B-fueron identificados inicialmente en el occidente de las Sierras Grandes (Pastor, 2012). Un análisis cuantitativo indica que es el canon $\mathrm{C}$, considerado como la resolución formal que le otorga especificidad a la localidad, el que domina con el 66,9\% (N: 324). Está caracterizado por los elaborados adornos dorsales, que en ocasiones no guardan relación con las dimensiones del individuo que lo porta. Finalmente, dentro del grupo de los objetos se observan dos tipos que se caracterizan por la ejecución de una parte de la figura humana, los mascariformes, individualizados solo por sus adornos o tocados cefálicos (Figura 4).

Finalmente, los no figurativos o geométricos reúnen el $34.86 \%$ (N: 1472) y están en la mayoría de los sitios (N: 50). Presentan una marcada variabilidad, ya que identificamos 26 tipos divididos entre circulares, cuadrangulares, lineales, estrellados, irradiados, puntifomes, elipsoidales, figuras sinuosas y complejas, entre otras. A su vez, están divididos en subtipos entre los que predominan aquellas figuras que representan una simplificación de todos los elementos. Círculos, líneas rectas, sinuosas y escalonadas, líneas de puntos y de trazos, puntos aislados y cuadriláteros constituyen el 64.53\% (N: 950). Esta situación marca una nueva redundancia al interior del repertorio, dado que lo común y compartido son estas formas básicas que adquieren expresiones particulares a partir de la combinación de elementos (p.e., líneas rectas con apéndices lineales alternados).

Un dato que habilita un acercamiento al estudio del tiempo involucrado en la ejecución de las representaciones es el análisis de los procesos de conformación de los paneles, ya que éstos no son el resultado de un acto único sino del agregado tanto de 


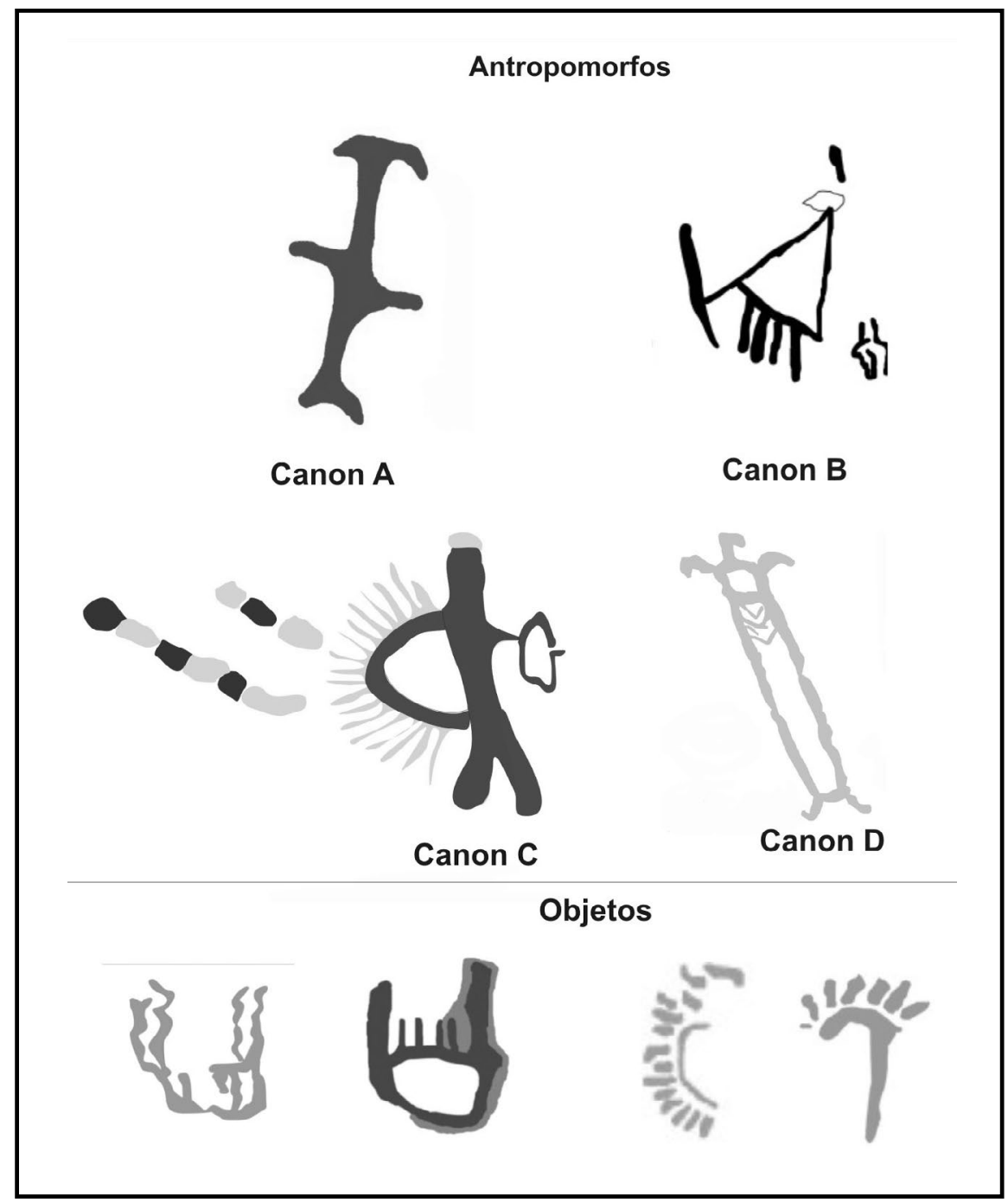

Figura 4. Cánones de motivos antropomorfos y objetos documentados en la localidad de Cerro Colorado.

representaciones aisladas como de diferentes escenas y temas que completan lo anterior. Este proceso de construcción constante y diferida da lugar a una cierta redundancia iconográfica así como a la incorporación de narrativas particulares a lo previo, particulares por la selección de motivos específicos y de escasa circulación o de una determinada resolución formal. En este punto, las diferencias de tono (Gradin, 1978; Aschero, 1994) de los colores observadas en la mayoría de los motivos, asociaciones y temas indican que muchos fueron realizados en momentos sucesivos. En concreto, la incorporación de rasgos diferentes o complementarios en los paneles sugiere un proceso de significación constante, el cual po- siblemente tenía lugar cada vez que las personas o grupos ocupaban los sitios. Fue este acto rutinario generado a partir de la articulación de los espacios con arte con los entornos domésticos (poblados/ áreas de cultivo/áreas de molienda), lo que permitió que los sitios con representaciones llegaran a ser lugares en los cuales se negociaba, reforzaba y resignificaba la memoria, la historia y la identidad del o los grupos que los construyeron. Es precisamente este contexto el que nos permitirá proponer líneas de análisis a fin de comprender la incorporación de motivos particulares a las prácticas cotidianas desarrolladas en los abrigos con arte rupestre. 


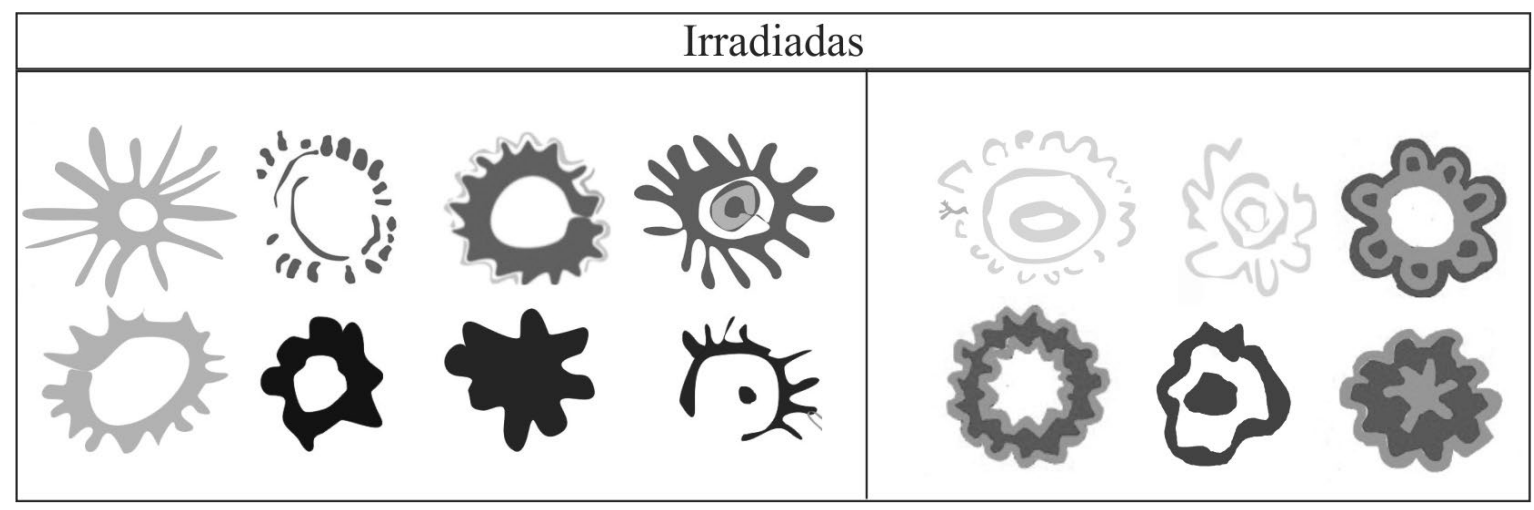

Figura 5. Detalle de algunas figuras irradiadas y sus variaciones.

El universo de irradiados en Cerro Colorado. Los casos de los sitios Los Tártagos 2 y Vaca Errana 3

En un repertorio que, como describimos en el apartado anterior, está caracterizado por una parte por el predominio de figuras como camélidos, antropomorfos, geométricos, y por otra, por la gran variabilidad que sobresale en sus definiciones formales, queremos señalar la presencia de una que se destaca entre las no figurativas: la figura irradiada (Figura 5). Este subtipo tiene una amplia distribución en todas las formaciones, lo que lo convierte en un elemento sensible sobre el cual identificar aquellos diseños que rompen con los parámetros extendidos en el tiempo y el espacio de Cerro Colorado. Las definiciones básicas o simples de las figuras irradiadas presentan una forma circular (simple o concéntrica) de la que se desprenden trazos paralelos (los llamados "soles"). En el interior de este subtipo identificamos un diseño que en cierta medida rompe con esta asociación de elementos, ya que si bien dos se resuelven sobre la base de un círculo, el motivo resulta de la combinación de trazos cuadrangulares continuos, semejantes a engranajes, o como semicírculos dispuestos en toda la circunferencia, lo que les proporciona una apariencia de flores (Figura 5).

Estas definiciones formales de las figuras irradiadas están presentes solo en dos de los 54 sitios que integran la localidad: Los Tártagos 2 (LT2), también denominado alero de Don Ata, y Vaca Errana 3 (VE3) o Alero de los Soles (ver Figura 1). El primero está emplazado en la margen derecha del río Los Tártagos, a menos de $2 \mathrm{~km}$ del pueblo de Cerro
Colorado, y en la parte baja de la ladera del cerro Bola. Se trata de un alero sobreelevado y "oculto" a la mirada directa de aquel que circula por el paisaje. Sus dimensiones son de $3 \mathrm{~m}$ de ancho por $2.3 \mathrm{~m}$ de profundidad y está conformado por tres paneles (Figura 6), distribuidos en diferentes sectores del soporte, entre los que registramos un total de 71 motivos. El sitio no tiene otras evidencias de ocupación, aunque está emplazado a $500 \mathrm{~m}$ de un área de molienda (instrumentos fijos $\mathrm{N}$ : 13). VE3 se ubica en una quebrada que corta transversalmente la ladera sur del cerro Vaca Errana, condición que lo convierte en visible, en tanto accesible, solo para aquellos que se trasladan al sitio. El abrigo cuenta con tres morteros de dimensiones variables $(10 \mathrm{~cm}$ a $18 \mathrm{~cm}$ de profundidad) y está ubicado a menos de $700 \mathrm{~m}$ de una dispersión superficial de artefactos, la cual está vinculada a un terreno potencialmente cultivable. Es un alero de dimensiones considerables, de $7.5 \mathrm{~m}$ de ancho y $3.5 \mathrm{~m}$ de profundidad, donde se distribuyen, en 11 sectores de dimensiones diversas, 243 representaciones (Figura 7).

Entre los tipos identificados en ambos sitios están presentes los camélidos, antropomorfos y los no figurativos en toda su expresión, es decir, rasgos que son comunes a la localidad y algunos que referencian elementos sensibles del repertorio por su importancia cualitativa (p.e., cóndores y felinos) (ver Figuras 6a y $7 \mathrm{a}$ y b). No obstante, observamos una leve diferencia en cuanto a la importancia cuantitativa de los tipos de motivos dominantes, ya que en el sitio LT2 son claramente los zoomorfos, y específicamente los camélidos, los mayoritarios (Tabla 1), mientras que 
Tabla 1. Distribución de los tipos de motivos entre los sitios analizados. *No están contabilizados los indefinidos.

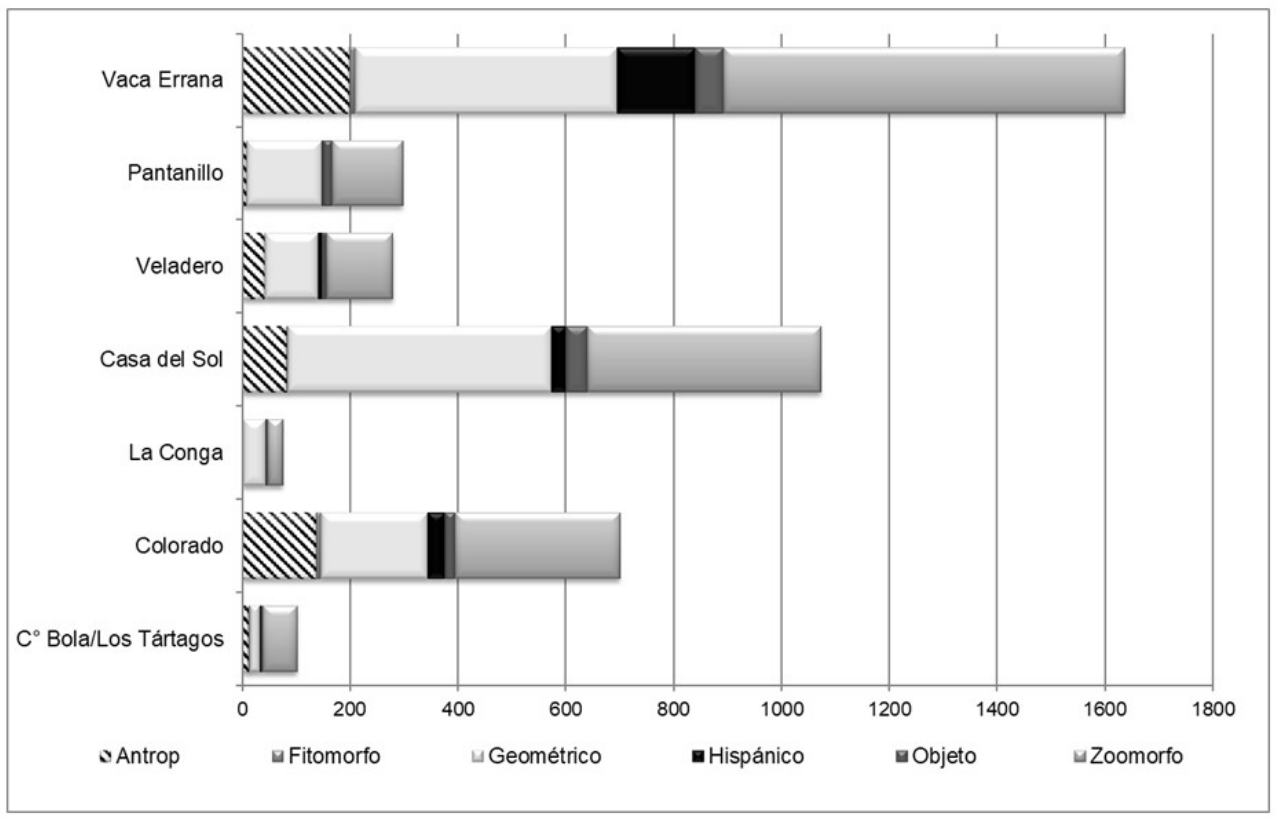

esta situación se revierte en el sitio de VE3 o Alero de los Soles, ya que predominan levemente los no figurativos con el 45.68\% (Tabla 1). No obstante, al igual que en LT2, son los camélidos los animales mayoritarios, esto es, la figura que tiene una amplia circulación en el paisaje.

En el caso de LT2 observamos que a una temática constituida por líneas de puntos, antropomorfos C, camélidos (A, I y J) en negro (Figura 6a), que por su posición, distribución y tamaño ocupa un lugar central en el soporte, fueron incorporados en otros sectores del abrigo los temas en blanco que involucran los motivos irradiados, que se presentan como desagregados de esta narrativa (Figura 6b y c). Estas figuras dispuestas en el panel LT2b son dos, la primera identificada como diseño de flor en el cual se distinguen seis pétalos (Figura 6b); por otro lado, la segunda resulta a partir de círculos concéntricos, cuenta con 16 apéndices subcuadrangulares (Figura 6c). Estas dos representaciones se vinculan con rasgos del repertorio que son importantes cuantitativa y cualitativamente, ya que se trata de motivos constantes y repetidos como camélidos de canon A, un felino y otros no figurativos (línea escalonada y círculo) (Figura 6b y c; Tabla 1).
Respecto al tiempo involucrado en la ejecución de las representaciones, es posible analizar dos variables, superposiciones y diferencias tonales como indicadores de eventos relativamente diacrónicos. En el sector central identificamos superposiciones netas (líneas de puntos sobre camélidos previos) y complementarias (sensu Gallardo, 2001), dado que se usa un motivo previo para la elaboración de otro camélido, más grande. Por otra parte, y a pesar del estado regular de conservación debido al exceso de humedad que se filtra por el soporte, pudimos percibir tonalidades diferentes entre el negro y el blanco de algunos de los motivos involucrados (Figura 6). Así, fundamentalmente en el panel $2 \mathrm{~b}$ observamos que un camélido de reducidas dimensiones fue integrado a una de las figuras irradiadas (Figura 6c). Esto da cuenta de que las asociaciones identificadas en los distintos sectores del soporte pueden ser el resultado de eventos relativamente diferentes de ejecución, aun cuando no sea factible definir los tiempos involucrados en la realización de los paneles.

En el sitio VE3, el proceso de construcción es más complejo, ya que se desenvuelve en 11 sectores distribuidos a lo largo del soporte. Los motivos irradiados están presentes en siete (Figura 7), pero para 

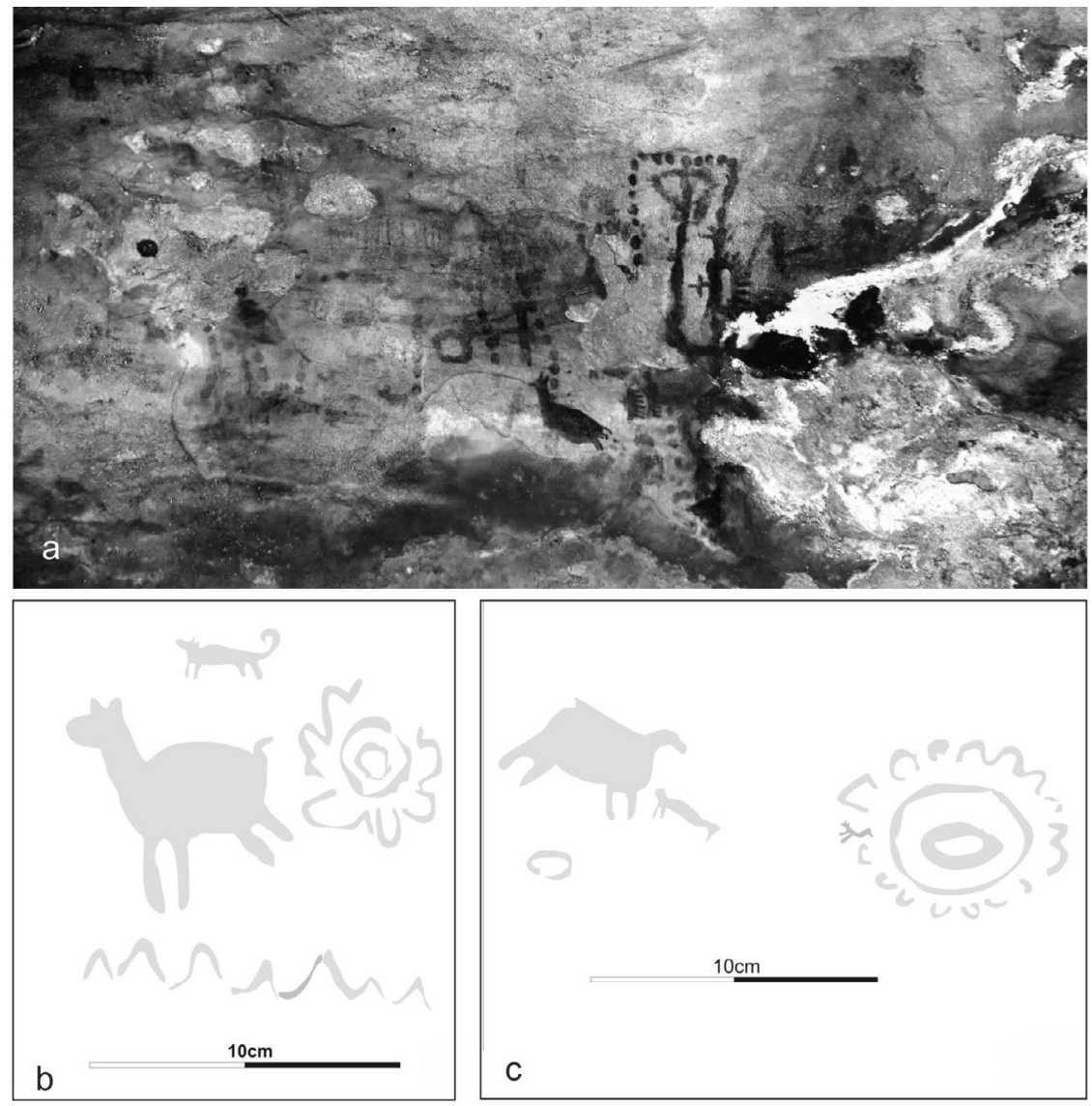

Figura 6. a) Panel central de LT2; b y c) Detalles de los motivos irradiados.

los fines de este trabajo, solo consideraremos uno en el cual están claramente representados aquellos que rompen con las resoluciones definidas como usuales para la localidad (Figura 7c). En el panel seis de VE3, identificamos 16 representaciones en blanco, rojo y negro y, a diferencia de lo que mencionamos como característica para el sitio respecto del predominio de los no figurativos, aquí ese lugar es compartido por varios tipos de motivos dado que ocho son geométricos, cuatro camélidos, dos mascariformes y dos antropomorfos (Figura 7c). Entre los segundos individualizamos dos cánones, uno mayoritario en las resoluciones de camélidos como el A y otro que, aunque cuantitativamente menor, constituye una expresión local, éste es el H. Por otra parte, existe una clara conexión entre los antropomorfos y objetos, dado que están representados en el canon D (cuerpo alargado y repartido en el medio con adornos cefálicos y piernas realizadas mediante trazos finos y curvos) y la expresión mínima o simplificada de esta figura en los mascariformes (Figura 7c). Por consiguiente, nuevamente en este caso son elementos que se integran al repertorio que circula en la localidad y que constituyen rasgos que integran una narrativa común. Este panorama se completa con el análisis de dos de los geométricos presentes, las líneas escalonadas dobles. En este contexto fueron incorporados los cinco irradiados a VE3 que están caracterizados porque cada uno tiene una resolución formal única y diferente del otro. Mediante la combinación y juego entre el rojo y el blanco, están distribuidos semicírculos o rasgos subcuadrangulares dispuestos en toda la circunferencia (flores y engranajes). Dos corresponden a formas de flores, pero se diferencian por la cantidad de pétalos, ya que uno presenta siete externos y nueve que se replican en el área interna, mientras que el otro tiene 13 externos (motivos 2 y 3, Figura 7c). Los tipos engranajes son tres y cuentan dos con 10 y uno con 15 rasgos subcuadrangulares (motivos 1, 4 y 5 , respectivamente; 

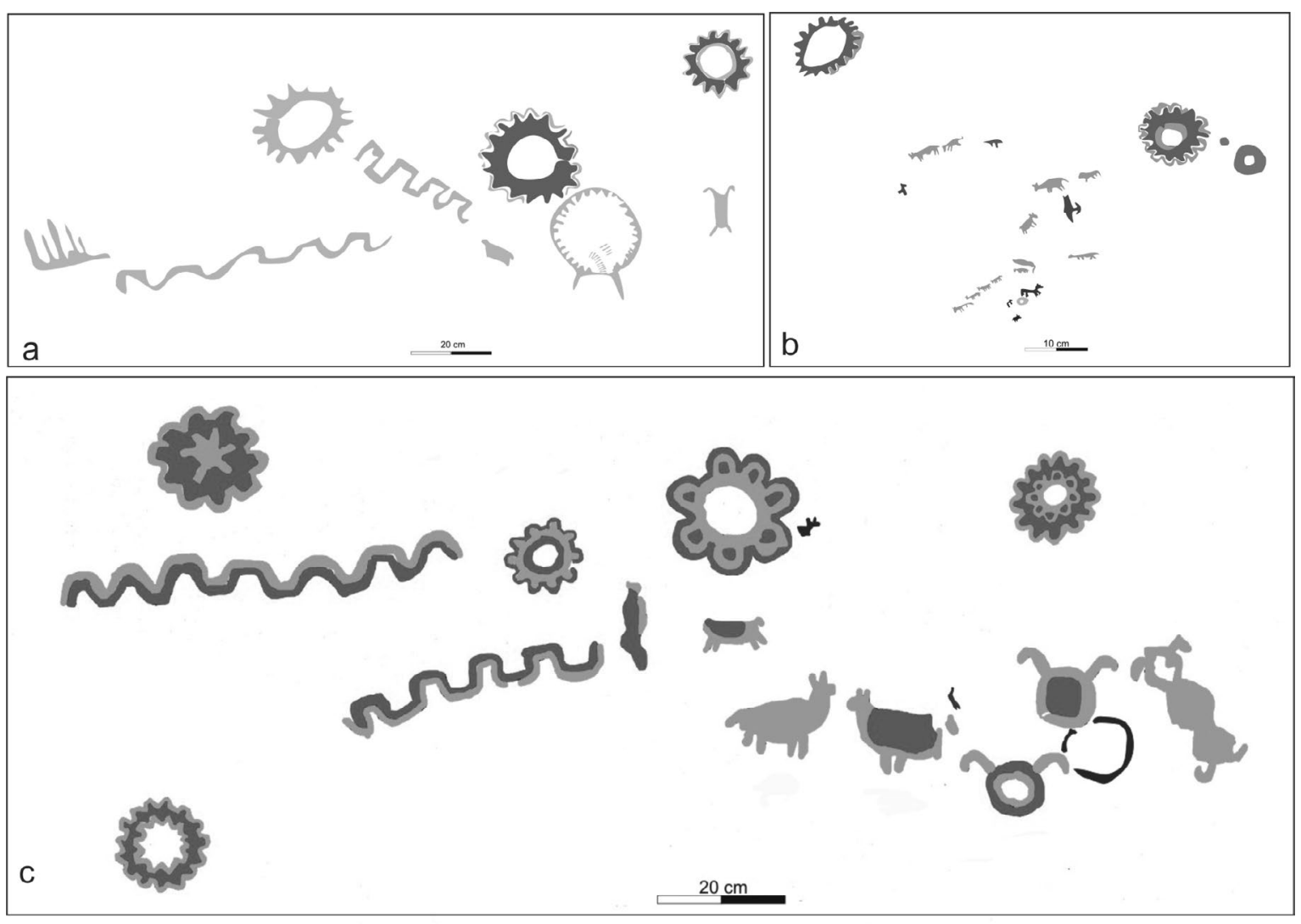

Figura 7. a y b) Detalles de los paneles que integran el sitio VE3; c) subtipos de motivos irradiados del panel 6 de VE3.

Figura 7c). En este último caso, las resoluciones presentan diferencias en las definiciones internas, puesto que una tiene una forma circular (2), otra con una replicación interna del engranaje (3) y la tercera con una forma estrellada (5) (Figura 7c).

\section{Repertorios en contexto regional y macrorregional}

El diseño particular de los motivos irradiados llevó a poner en juego las resoluciones identificadas en el área norte y en la región centro-oeste de Sierras Centrales, a fin de buscar en el repertorio conocido elementos que nos permitieran marcar semejanzas con los identificados en el arte rupestre de Cerro Colorado y, junto con esto, respaldar la circulación de rasgos comunes a nivel regional. En este punto resulta oportuno aclarar que las particularidades ambientales y del suelo de toda la región impiden la conservación de artefactos de origen orgánico (cuero, madera, textiles), lo que genera un sesgo imposible de traspasar, ya que solo podemos comparar las representaciones rupestres con una parte de los posibles artefactos en los que se objetivaban y negociaban las narrativas identitarias (cerámica, hueso, piedra).

En el repertorio rupestre presente en el área centrooeste hemos identificado, como mencionamos en apartados anteriores, claras semejanzas en algunos cánones de camélidos y antropomorfos. En tanto, entre los no figurativos predominan las formas básicas, círculos (con punto central, concéntricos o con apéndices), líneas, puntos y figuras complejas; en concreto, diseńos que, en mayor o menor medida, están presentes en Cerro Colorado (Recalde, 2009; Pastor, 2012; Tissera, 2016). Incluso algunos de los denominados "soles" fueron reconocidos entre las representaciones del área, pero ninguno de ellos se 


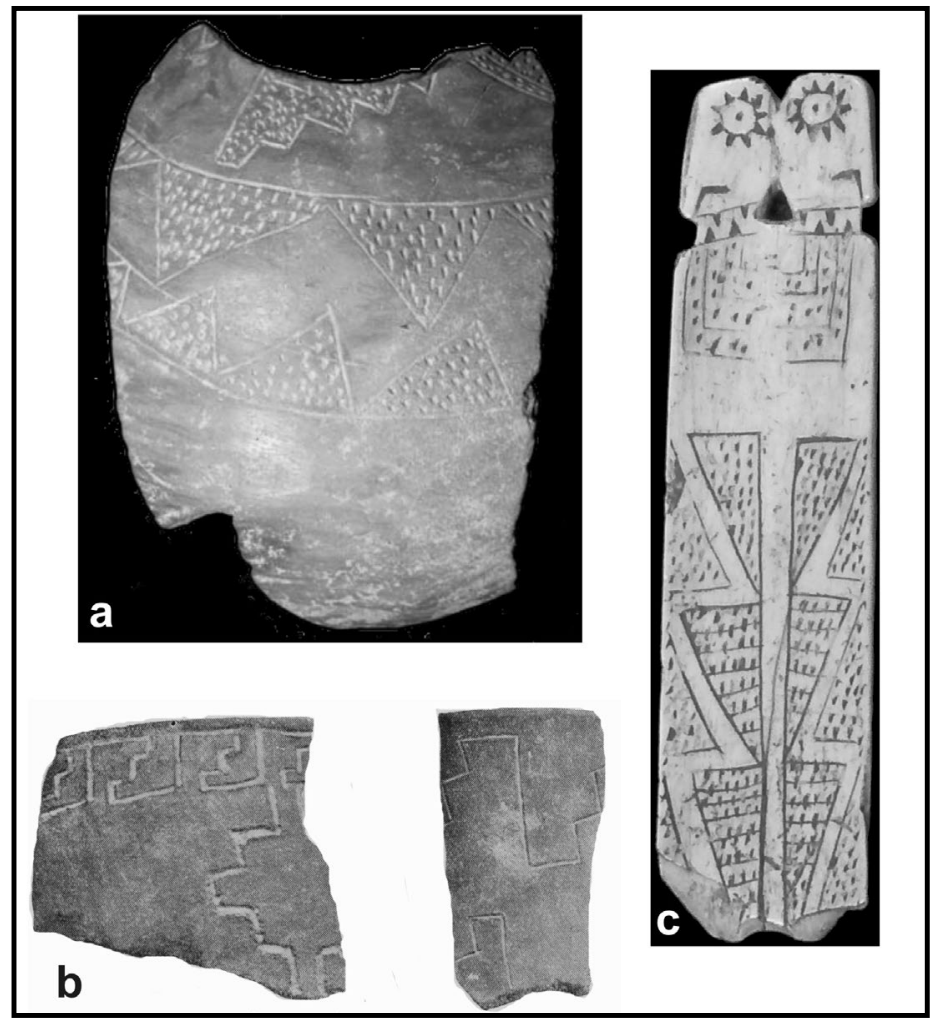

Figura 8. a y b) Fragmentos cerámicos en los que se destacan los diseños geométricos; c) Adorno de hueso con motivos geométricos y zoomorfo; a y c, tomadas de Bixio y cols., 2010; b, tomada de Serrano, 1945).

asemeja a las resoluciones tipo pétalos o engranajes de los abrigos pintados de la localidad arqueológica del norte serrano.

Uno de los soportes muebles más conspicuos son los recipientes cerámicos. Los motivos "serranos cordobeses" son fundamentalmente incisos y se resuelven mediante la combinación de formas geométricas simples o básicas, esto es, líneas rectas y escalonadas, que se presentan de manera aislada o se combinan conformando guardas de líneas dobles o triples, figuras de triángulos o cuadrangulares. Estas formas pueden presentar campos vacíos o rellenos, realizados por la incisión de puntos o trazos cortos mediante surco rítmico (Figura $8 \mathrm{a}$ y b). A estas definiciones básicas identificadas inicialmente por Serrano para el área central $(1945,1958)$, podemos agregar algunas variaciones locales que resultan de la complejidad y frecuencia con la cual estos elementos se conjugan (p.e., Argüello de Dorsch, 1983; Berberián, 1984). En casos extremos, a pesar de seguir estos patrones comunes, la variación llega a tener expresiones puntuales o locales tan disímiles que denotan una ausencia de estandarización en el repertorio (Medina, 2010). Se han identificado también recipientes decorados mediante la aplicación de pintura en la superficie, pero en forma mayoritaria responde a una capa uniforme tipo engobe (Dantas y Figueroa, 2008; Medina, 2010). El dato más significativo es que los repertorios se distribuyen por igual tanto en contextos domésticos como en espacios de interacción extracomunales (Dantas y Figueroa, 2008; Medina, 2010), lo cual implica ámbitos de circulación que involucran diferentes esferas de acción social y en consecuencia, prácticas y actores distintos que comparten maneras particulares de interpretar y construir el mundo que los rodea.

Otro de los artefactos cerámicos que presenta decoración son los torteros, objeto cuyos diseños permitirían definir una relación directa con las muyunas santiagueńas. Comunes en los espacios domésti- 


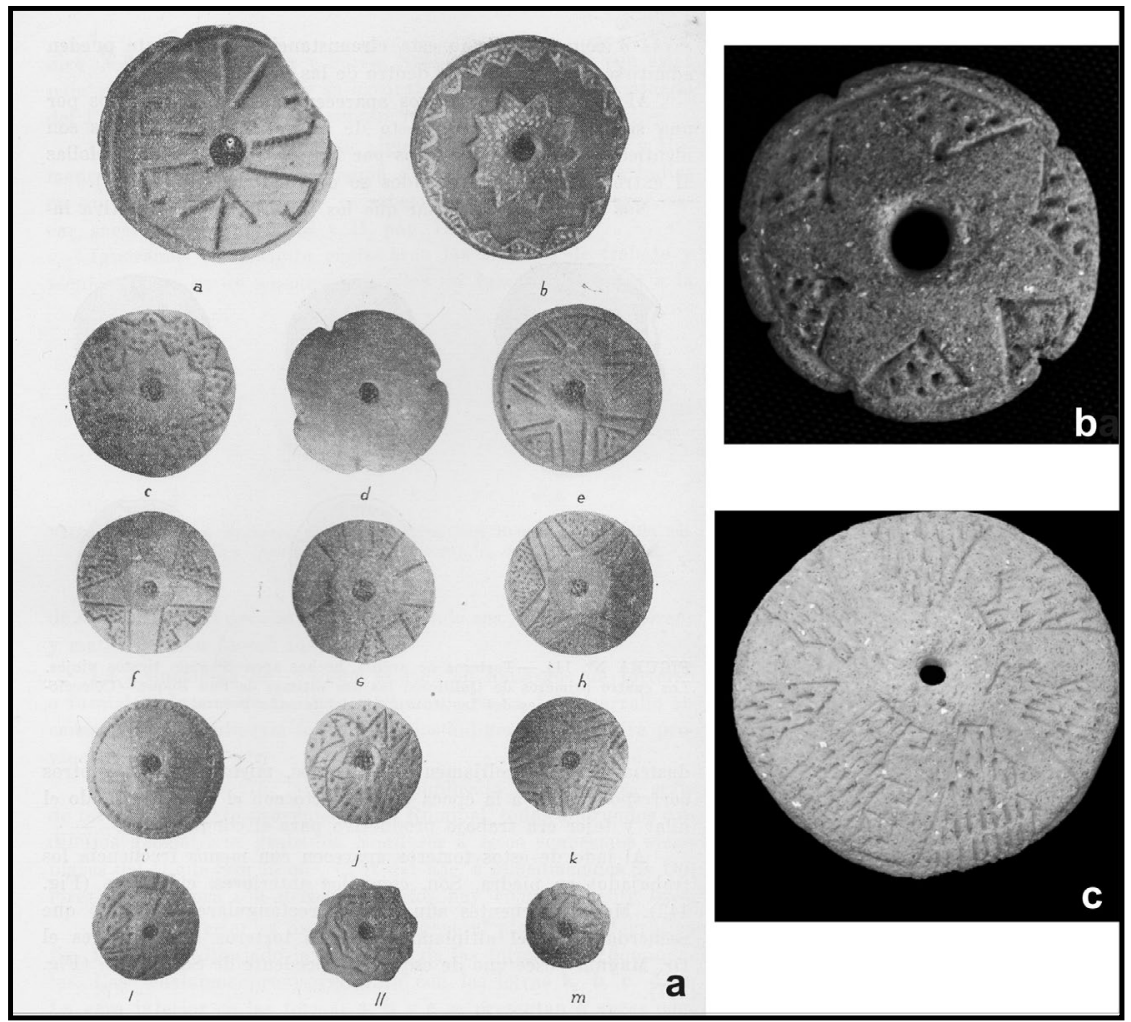

Figura 9. a, b y c) Torteros procedentes de la región central de las Sierras Centrales; a, tomado de Serrano, 1945; b, colección de la Estancia de Jesús María - Museo Jesuítico Nacional; c, tomado de Bixio y cols., 2010).

cos de las comunidades prehispánicas tardías de las Sierras Centrales, constituyen uno de los pocos instrumentos vinculados con la práctica textil que ha perdurado en el registro arqueológico del área. ${ }^{5}$ En su gran mayoría son de cerámica, aunque se han documentado algunos pocos ejemplares de hueso y piedra (Serrano, 1945). Las formas dominantes son las circulares, elaboradas como piezas únicas o realizadas con fragmentos de vasijas, mientras que las de hueso y piedra son rectangulares. El análisis de los diseños efectuados sobre estos instrumentos aporta datos substanciales a la hora de contrastar nuestra hipótesis respecto a la procedencia desde las llanuras santiagueńas de los motivos irradiados analizados en el arte rupestre de Cerro Colorado. Las resoluciones

5 Existen referencias en las fuentes documentales respecto a la actividad textil entre los grupos indígenas locales. Así, la Relación Anónima dice: “...gente toda la más vestida dellos con lana y dellos con queros labrados [...] las camisetas que traen vestidas son hechas de lana y tejidas primorosamente...” (Levillier, 1930, p. 321). identificadas en algunos de los artefactos recuperados en la región de las Sierras Centrales (González, 1943; Serrano, 1945) se resuelven sobre la base de la combinación de los mismos elementos aislados en las vasijas cerámicas; en concreto, líneas rectas y quebradas que se conjugan en la conformación de triángulos y cuadrangulares, con campos vacíos o rellenos de puntos (Figura 9). De los ejemplares destacados por González (1943) llaman la atención aquellos con figuras irradiadas simples (Figura 9b) y dobles, en positivo o negativo (Figura $9 \mathrm{a}, \mathrm{b}$ y c). Estos diseños resultan análogos a los identificados en el arte rupestre del panel 6 de VE3, fundamentalmente el definido como tipo engranaje (Figura 7c, motivo 5). Asimismo, uno de estos artefactos tiene una forma levemente irradiada (Figura 9a, 11). No obstante estas similitudes, no se han documentado diseños parecidos a las representaciones rupestres con apéndices de pétalos o engranaje conformados por extensiones cuadrangulares. En Cerro Colorado solo hemos recuperado fragmentos de torteros sin 
decoración y entre los ejemplares que se encuentran en la reserva del Museo Arqueológico de la localidad solo dos presentan decoración tipo Averías, dado que están realizados sobre fragmentos de vasijas.

Finalmente, otros artefactos elaborados en hueso y piedra exhiben diferentes diseños, pero sin guardar relación con las definiciones de motivos geométricos tratados para LT2 y VE3 (Figura 8c). En este material se confeccionaron numerosos artefactos como puntas de proyectil con zoomorfos, punzones con figuras de ofidios, adornos con motivos lineales, tubos con representaciones geométricas. En piedra se han documentado placas grabadas, instrumentos musicales y adornos con las mismas decoraciones lineales identificadas en la cerámica (González, 1943; Serrano, 1945; Argüello de Dorsch, 1983; Berberián, 1984; Bixio et al., 2010) (Figura 8). En casi todos estos casos se trata de objetos que contienen rasgos básicos que circulan entre diferentes soportes, esferas y prácticas sociales (doméstico/comunitaria), esto es, entre ámbitos interconectados en la construcción de una manera común de interpretar la realidad circundante.

En concreto esta ausencia de los diseños de flores y engranajes en los distintos soportes y artefactos recuperados en diferentes áreas de las Sierras Centrales nos llevó a la búsqueda de referentes macrorregionales que nos permitieran ampliar los parámetros comparativos y proponer líneas respecto a su procedencia. Los vínculos o conexiones sociales extrarregionales entre las comunidades del norte de las Sierras de Córdoba fueron propuestos siempre de forma indirecta por varios investigadores (p.e., González, 1963, 1977; Pérez Gollán, 1968; Schobinger y Gradin, 1985). En esta línea Pérez Gollán (1994, p. 37) plantea la vinculación de las Sierras del Norte con la cuenca del río Dulce por el llamado "camino de Santiago del Estero o de los sanavirones" mediante caravanas de llamas. Asimismo, este autor sostiene también la circulación y conexión con Catamarca (Pérez Gollán, 1994), posiblemente a través del corredor biogeográfico ubicado en las Salinas Grandes que permite unir la región de Ancasti con el norte cordobés. En este punto, vale destacar el hallazgo de cerámica decorada con patrones asimilables a los diseños serranos cordobeses en ambas regiones (El
Alto-Ancasti y las llanuras santiagueñas; ver Figura 1) (Lorandi, 2015; Gheco, 2016). Junto a esta propuesta, otras evidencias en la zona occidental de las Sierras Grandes constituyen indicadores de contactos y circulación de ideas y personas con la posible presencia de hojas de coca boliviana en un contexto de ocupación estacional estival fechado en $1300 \mathrm{AP}$ (Recalde, 2015b), especie vegetal que planteaba la existencia de redes de interacción con las regiones de Aconquija (Tucumán) y/o El Alto-Ancasti (Catamarca) (López y Recalde, 2016). En esta área se definieron también vínculos y lazos sociales con los llanos de La Rioja a partir de semejanzas estilísticas y por el análisis de topónimos y antropónimos locales recuperados de las fuentes etnohistóricas (Pastor y Boixados, 2016).

Concretamente, las investigaciones desarrolladas en la región de Cerro Colorado están proporcionando datos empíricos que comienzan a respaldar estas conexiones extrarregionales. En este sentido, la presencia de quinoa (Chenopodium quinoa var. quinoa) en el sitio QN7, emplazado a $5 \mathrm{~km}$ del actual pueblo Cerro Colorado constituye un indicador claro de vínculos con la región del Noroeste ya que sus características morfológicas señalan esta procedencia (López y Recalde, 2016). En esta misma línea, las particularidades técnicas y de diseño de fragmentos cerámicos recuperados en contextos vinculados a un panel con representaciones y a un poblado tardío excavados en la localidad arqueológica indicarían vínculos con la región de Santiago del Estero (decoración negro sobre ante y pintura naranja). ${ }^{6}$

Dentro de este contexto, una primera mirada general sobre el conjunto artefactual de las tierras bajas de Santiago del Estero, fundamentalmente del área del río Salado Medio (Taboada y Angiorama, 2010; Taboada et al., 2013; Taboada, 2014), nos permite comenzar a identificar diseños concretos sobre los cuales reconocer claras recurrencias. Así, en el marco de la gran variabilidad tecno-morfológica de

6 Las escasas dimensiones limitan las posibilidades de determinar con exactitud si se trata de diseños Sunchituyoj o Averias de Santiago del Estero. No obstante, a pesar de la secuencia cronológica tradicional para ambos tipos cerámicos, se ha planteado la coexistencia y perduración del primero con el segundo (Taboada y Angiorama, 2010; Lorandi, 2015). 


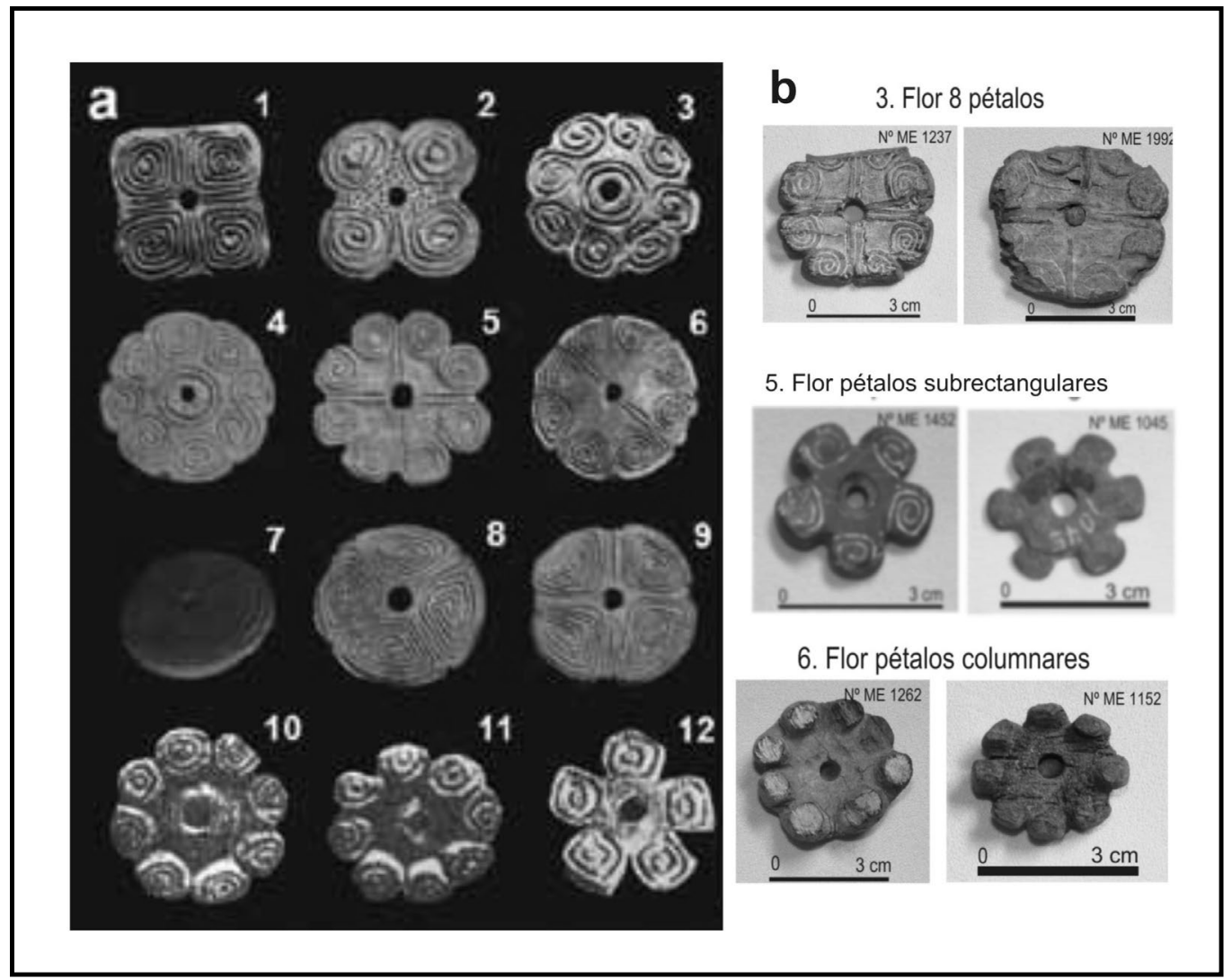

Figura 10. a) Torteros procedentes de diferentes sitios de Santiago del Estero;

b) variantes 3, 5 y 6 de los torteros recuperados en La Paya, en el valle Calchaquí; a, tomado de Taboada y cols., 2013; b, modificado de Sprovieri, 2014.

los torteros o muyunas provenientes de diferentes sitios de la región (López Campeny, 2010-2012), como destacamos inicialmente, hay algunas variantes factibles de vincular con las figuras rupestres de Cerro Colorado. Resultan llamativas así las resoluciones formales de los torteros ejecutados mediante el agregado de pétalos o pétalos subcuadrangulares, dispuestos en número de cuatro a ocho alrededor de la circunferencia (Figura 10a). De la misma manera, y como fuera destacado por Taboada y Angiorama (2010) para algunos de estos diseños santiagueños, estas similitudes habilitan incluso para fijar interacciones de mayor rango, dadas las semejanzas con los diseńos de pétalos identificados como variantes 3, 5 y 6 para el sitio de La Paya en el valle Calchaquí (Sprovieri, 2014) (Figura10b). En este punto, también la asignación cronológica a momentos tardíos e incaicos (Taboada et al., 2013; Sprovieri, 2014) permite fijar claras corresponden- cias temporales con los motivos rupestres de Cerro Colorado. Vale aclarar que con esta comparación no estamos planteando la conexión directa del norte de Córdoba con el incario sino que, a partir de lo propuesto por Taboada y Angiorama (2010), es probable que las comunidades de la llanura fueran las que establecieran las líneas de interacción hacia afuera del actual territorio de Santiago del Estero, dando lugar a un flujo de personas e información que traspasaba los límites materiales suscitados por las relaciones directas con el incario.

Asimismo, los documentos hispánicos anteriores a la fundación de la ciudad de Córdoba (1573) y la información derivada de las investigaciones lingüísticas sobre la base del análisis de los topónimos locales también sugieren las conexiones tardías con los denominados "sanavirones", que ocupaban la jurisdicción del río Dulce en la actual provincia de 
Santiago del Estero, y que se habían extendido a lo largo de toda la región serrana cordobesa (Bixio, 1998). ${ }^{7}$

Toda la información recuperada a partir de este primer análisis iconográfico nos habilita a pensar líneas de indagación concretas respecto a los vínculos basados en el parentesco o pertenencias comunes con dinámicas sociales más intensas de las que originalmente se pensaba.

\section{Consideraciones finales}

El repertorio rupestre de Cerro Colorado está dominado por elementos compartidos que, aun cuando presentan resoluciones de diseño disímiles, tienen una marcada circulación entre los sitios que integran la localidad, los cuales objetivan una manera común de pensar y vivir el mundo social que los rodea. Estas maneras de hacer constituyen también una de las expresiones materiales actuantes en la construcción cotidiana de la identidad. La incorporación a las prácticas rutinarias de los sitios con arte rupestre, sugerido tanto sobre la base de la articulación con los espacios comunitarios (poblados, molienda, cultivo) como de la condición de visualización que se tiene desde los paneles a este entorno común, proporcionaba las bases para una activación constante de los procesos de negociación, reforzamiento y resignificación de pertenencias. En este contexto, la circulación de rasgos o diseños poco frecuentes en el registro aluden a la edificación de identidades hacia el interior de los grupos domésticos o unidades sociales reducidas (Recalde, 2015a). Ambas expresiones, ambas narrativas, no son excluyentes, pues

7 Bixio y colaboradores (2010) proponen que los sanavirones habían penetrado en la región cordobesa de manera reciente, hasta el punto que en el año 1598 todavía los indígenas autóctonos recordaban los cambios operados por su presencia. Incluso, este contexto llevó a postular a Bixio (2008), en contraposición de lo que sostiene Montes (2008) respecto a diferentes oleadas migratorias, que posiblemente el movimiento de los grupos asentados en la zona sur de Santiago del Estero fuera la consecuencia de la presión ejercida por la conquista espańola. Como ocurre con otras construcciones étnicas generadas por la colonia (p.e., Faberman y Taboada, 2012), en este caso las distinciones lingüísticas tampoco están acompañadas por diferencias en la materialidad (Bixio et al., 2010). la presencia de elementos que no tienen un anclaje aparente en el mundo social del cual forman parte puede interpretarse como una manera de acordar y construir sentidos nuevos de integración, edificados a partir de circunstancias históricas cambiantes. En este punto, la incorporación de los diseńos irradiados considerados como foráneos (engranajes o flores), en tanto ausentes o inexistentes en el repertorio del área norte como centro-oeste de Sierras Centrales, a paneles donde registramos motivos y definiciones formales recurrentes (p.e., camélidos, antropomorfos), dan cuenta de la coexistencia de varias expresiones identitarias, entre las cuales las referencias a lazos sociales o parentales más acotados no niegan la pertenencia a una comunidad.

Paralelamente, la incorporación de estos diseños irradiados en el universo iconográfico local o regional nos permitió comenzar a establecer conexiones más allá de las "fronteras cordobesas" prehispánicas. La diversidad de datos, aunque iniciales, apuntalan la existencia de vínculos extrarregionales, probablemente como lazos sociales forjados a lo largo del tiempo (el cultivo de la quinoa, como especie alóctona, podría haber estado presente hacia ca. 1200 $\mathrm{AP})$, pero que tuvieron su máxima expresión en el arte rupestre de Cerro Colorado en momentos tardíos del proceso histórico local. Es decir que, dada la cronología también tardía planteada para la mayoría de los torteros, y fundamentalmente para aquellos que presentan características similares a las pinturas (p.e., Taboada y Angiorama, 2010; Sprovieri, 2014), los motivos se habrían incorporado al repertorio de Cerro Colorado en el marco del proceso de intensificación de las tensiones sociales en la región serrana cordobesa a finales del PPT. Estas concordancias temporales no implican asumir que la adopción de los diseños fue acompañada de los mismos sentidos, sino que claramente fueron redefinidos en el marco histórico específico (Kopytof, 1989). Así la integración de estas resoluciones en una frecuencia tan baja, dado que constituyen el $0.58 \%$ sobre el total de no figurativos y que están presentes solo en algunos de los paneles de LT2 y VE3, junto a la particularidad de su emplazamiento, ya que resultan accesibles solo a las personas que ocupan los abrigos y que, a diferencia de la mayoría de los sitios con arte rupestre de la localidad, no permiten una visualización ha- 
cia entornos comunitarios, constituyen las líneas de evidencia que autorizan a proponer su construcción como espacios de expresiones identitarias particulares, casi exclusivas a aquellos que significaban cotidianamente esos lugares.

En suma, estos nuevos referentes iconográficos actuaron en el fortalecimiento y demarcación hacia adentro y también hacia fuera del/los grupo/s que los ejecutaron en los paneles a partir de la referencia y objetivación, por medio de estos diseños, de los vínculos y lazos establecidos con entidades políticas o parentales ubicadas, por ejemplo, en la llanura santiagueña.

\section{Agradecimientos}

Quisiera agradecer a Sara María Luisa López Campeny y a Carolina Agüero Piwonka la invitación para participar en este volumen temático. También a los/las evaluadores/ras anónimos, cuyos aportes permitieron mejorar la versión original. Finalmente, a Luis Tissera, Director del Museo Arqueológico Cerro Colorado, por facilitar el acceso a la colección arqueológica. Este trabajo fue realizado en el marco de los proyectos financiados por CONICET (PIP 11220120100381CO) y por SECYT (30720150100747CB).

\section{Referencias citadas}

Argüello de Dorsch, A. (1983). Investigaciones arqueológicas en el Departamento Punilla (Provincia de Córdoba, Rep. Argentina). Sitio: C.Pun. 39. Comechingonia, 1, 41-60.

Aschero, C. (1994). ¿Adónde van esos guanacos? En Gómez Otero, J. (Ed.). Arqueología. Sólo Patagonia (pp. 153-162). Puerto Madryn: Centro Nacional Patagónico.

Augé, M. (1998). Los no lugares. Espacios del anonimato. Una antropología de la sobremodernidad. Barcelona: Gedisa.

Bauman, Z. (2005). Identidad. Buenos Aires: Losada.

Berberián, E. (1984). Potrero de Garay: una entidad sociocultural tardía de la región serrana de la provincia de Córdoba (República Argentina). Comechingonia, 4, 71-138.
Bixio, B. (1998). Identidades étnicas en Córdoba del Tucumán: 1573-1700. Tesis doctoral. Facultad de Filosofía y Humanidades, Universidad Nacional de Córdoba, Córdoba.

Bixio, B. y Berberián, E. (1984). Etnohistoria de la región de Potrero Garay (provincia de Córdoba, República Argentina). Comechingonia, 3, 11-46.

Bixio, B., Berberián, E. y Pastor, S. (2010). Historia prehispánica de Córdoba. Córdoba: Editorial Brujas.

Bolle, E. (1987). Parque arqueológico y natural de Cerro Colorado, Dpto. Tulumba, Provincia de Córdoba, República Argentina. Relevamiento de sitios con arte rupestre y análisis de los motivos pictóricos. Zona del Cerro Condorhuasi. Primera Parte: Nivel A Sitios Casa del Sol 1 al 16. Publicaciones del Instituto de Antropología, XLIV.

Bourdieu, C. (1977). Sur le pouvoir symbolique. Annales, Economies, Société, Civilisations, 32(3), 405-411.

Colqui, E. (2016). Primeras aproximaciones al análisis del arte rupestre de Quebrada Norte en el contexto de Cerro Colorado (Sierras del Norte, Córdoba). Zaranda de Ideas, 14(2), 73-92.

Criado Boado, F. (1996). En los bordes del paisaje. Del terreno al espacio: planeamientos y perspectivas para la arqueología del paisaje, 6, 1-63.

Dantas, M. y Figueroa, G. (2008). ¿Uniformidad o variabilidad tecnológica en la alfarería del sector centro-oeste de las Sierras Centrales (Córdoba-Argentina)? Arqueoweb. Revista sobre arqueología en Internet, 10.

Díaz, I., Pastor, S. y Barrientos, G. (2015). Conflicto y violencia interpersonal en las Sierras de Córdoba (Argentina) durante los siglos previos a la conquista europea. En Salazar, J. (Comp.). Condiciones de posibilidad de la reproducción social en sociedades prehispánicas y coloniales tempranas en las sierras pampeanas (República Argentina) (pp. 84-108). Editado por CEH. "Prof. SA Segreti”, Córdoba.

Díaz-Andreu, M. (2005). Gender identity. En Díaz-Andreu, M., Sam, L., Babic, S. y Edwards, D. (Eds.). The archaeology of identity. Approaches to gender, age, status, ethnicity and religion (pp. 13-42). London: Routledge. 
Domingo Sanz, I., Fiore, D. y May, S. K. (2009). Archaeologies of art: time, place, and identity in rock art, portable art, and body art. En Domingo Sanz, I., Fiore, D. y May, S. K. (Eds.). Archaeologies of art. Time, place, and identity (pp. 15-28). California: Left Coast Press.

Faberman, J. y Taboada, C. (2012). Las sociedades indígenas del territorio santiagueńo: apuntes iniciales desde la arqueología y la historia. Período prehispánico tardío y colonial temprano. Runa, 33(2), 113-132.

Gallardo, F. (2001). Arte rupestre y emplazamiento durante el Formativo Temprano en la cuenca del Río Salado (desierto de Atacama, norte de Chile). Boletín del Museo Chileno de Arte Precolombino, 8, 88-97.

Gardner, G. A. (1931). Rock-paintings of North West Córdoba. Oxford: Calderon Press.

Gheco, L. (2016). El laberinto de las paredes pintadas. Una historia de los abrigos con arte rupestre de Oyola, Catamarca. Tesis doctoral. Facultad de Filosofía y Humanidades, Universidad Nacional de Córdoba, Córdoba.

González, A. R. (1940). Las pinturas rupestres del Cerro Colorado (Provincia de Córdoba). Revista Geográfica Americana, año VII, vol. XIV (86), 333-336.

González, A. R. (1963). Las pinturas indígenas del Cerro Colorado. Gacetika, 63, 14-19.

González, A. R. (1977). Arte precolombino de la Argentina. Introducción a su historia cultural. Buenos Aires: Filmediciones Valero.

Gradín, C. (1978). Algunos aspectos del análisis de las manifestaciones rupestres. Revista del Museo Provincial, 1, 120-133.

Hastorf, C. (2003). Community with the ancestors: ceremonies and social memory in the Middle Formative at Chiripa, Bolivia. Journal of Anthropological Archaeology, 22(4), 305-332.

Jones, A. (2007). Memory and material culture. Cambridge: Cambridge University Press.

Kopytoff, I. (1986). La biografía cultural de las cosas: la mercantilización como proceso. En Appadurai, A. (Ed.). La vida social de las cosas. Perspectiva cultural de las mercancias (pp. 889-122). México D.F.: Grijalbo.
Kuijt, I. (2008). The regeneration of life. Neolithic structures of symbolic remembering and forgetting. Current Anthropology, 49(2), 171-197.

Levillier, C. (1930). Nueva crónica de la conquista del Tucumán. 1563-1573, Tomo II.

López, M. L. y Recalde, A. (2016). First quinoa (Chenopodium quinoa willd) botanical macro-remains at Sierras del Norte (Central Argentina) and its implications in pre-hispanic subsistence practices. Journal of Archaeological Science. Reports 8, 426-433.

López Campeny, S. M. (2011-2012). Retomando el hilo... los torteros arqueológicos de Santiago del Estero. Un giro a la discusión, primeros resultados y propuesta de investigación. Cuadernos del Instituto Nacional de Antropología y Pensamiento Latinoamericano, 23(1), 37-54.

Lorandi, A. M. (2015). Tukuma-Tukuymanta. Los pueblos del búho. Santiago del Estero antes de la Conquista. Santiago del Estero: Subsecretaría de Cultura de Santiago del Estero / Talleres del Boletín Oficial.

Lucy, S. (2005). Ethnic and cultural identities. En DíazAndreu, M., Lucy, S., Babic, S. y Edwards, D. Archaeology of identity. Approaches to gender, age, status, ethnicity and religion (pp. 86-109). New York: Routledge.

Medina, M. (2010). Tecnología cerámica, subsistencia y uso del espacio en el Tardío prehispánico de las Sierras de Córdoba (Argentina). Werkén, 13, 305-322.

Montes, A. (2008). Indígenas y conquistadores de Córdoba. Córdoba: Ediciones Isquitipe.

Pastor, S. (2007). “Juntas y cazaderos”. Las actividades grupales y la reproducción de las sociedades prehispánicas de las sierras centrales de Argentina. En Nielsen, A., Seldes, V., Vázquez, M. y Mercolli, P. (Comps.). Procesos sociales prehispánicos en el sur andino: la vivienda, la comunidad y el territorio, (pp. 361-376). Córdoba: Editorial Brujas.

Pastor, S. (2012). Arte rupestre, paisaje y tensión social: un caso de estudio de Córdoba, Argentina. Revista Chilena de Antropologia, 26, 7-32.

Pastor, S., Pautassi, E. y Rivero, D. (2005). Los sistemas de armas de las comunidades agroalfareras de Córdoba: una aproximación arqueológica y experimental. Actas del XIII Congreso Nacional de Arqueología Argentina, 4, 253-266. 
Pastor, S., Medina, M., Recalde, A., López, M. L. y Berberián, E. (2012). Arqueología de la región montañosa central de Argentina. Avances en el conocimiento de la historia prehispánica tardía. Relaciones, XXXVII(1), 89-112.

Pastor, S. y Boixados, R. (2016). Arqueología y etnohistoria: diálogos renovados en torno a las relaciones entre las sociedades de los Llanos Riojanos y de las Sierras Noroccidentales de Córdoba (períodos Prehispánico Tardío y Colonial Temprano). Diálogo Andino, 49, 311-318.

Pérez Gollán, J. (1968). Arte rupestre de Cerro Colorado. Buenos Aires: Filmediciones Valero.

Pérez Gollán, J. (1994). El proceso de integración en el valle de Ambato: complejidad social y sistemas simbólicos. Rumitacana, 1, 33-41.

Piana, J. (1992). Los indigenas de Córdoba bajo el régimen colonial (1570-1620). Dirección General de Publicaciones de la Universidad Nacional de Córdoba, Córdoba.

Recalde, A. (2009). Diferentes entre iguales: el papel del arte rupestre en la reafirmación de identidades en el sur del valle de Guasapampa (Córdoba, Argentina). Boletín del Museo Chileno de Arte Precolombino, 14(2), 39-56.

Recalde, A. (2015a). Representaciones en contexto. Características del paisaje rupestre de Cerro Colorado (Sierras del Norte, Córdoba, Argentina). Relaciones, XL(2), 523548.

Recalde, A. (2015b). Paisajes con memoria. El papel del arte rupestre en las prácticas de negociación social del sector central de las Sierras de Córdoba (Argentina). En Salazar, J. (Comp.). Condiciones de posibilidad de la reproducción social en sociedades prehispánicas y coloniales tempranas en las sierras pampeanas (República Argentina) (pp. 235-268). Editado por CEH. "Prof. SA Segreti”, Córdoba.

Recalde, A. y Pastor, S. (2011). Variabilidad y dispersión de los diseños de camélidos en el occidente de Córdoba (Argentina). Circulación de información, reproducción social y construcciones territoriales prehispánicas. Comechingonia, 15(1), 93-114.

Recalde, A. y González Navarro, C. (2015). Colonial rock art: a reflection on resistance and cultural change (17th Century-Córdoba, Argentina). Journal of Social Archaeo$\log y$, 15(2), 45-66.
Rivero, D. (2009). Ecología de cazadores-recolectores en el sector central de las Sierras de Córdoba (República Argentina). BAR International Series 2007, Oxford.

Rivero, D. y Recalde, A. (2011). El uso del arco en la guerra durante el Prehispánico Tardío de las Sierras de Córdoba. En Martínez, J. G. y Bozzuto, D. L. (Comps.). Armas prehispánicas: múltiples enfoques para su estudio en Sudamérica, pp. 151-171. Buenos Aires: FHN, Félix de Azara.

Schobinger, J. y Gradín, C. (1985). Arte rupestre de la Argentina. Cazadores de la Patagonia y agricultores andinos. Madrid: Encuentro.

Serrano, A. (1945). Los comechingones. Serie Aborígenes Argentinos I, Publicación del Instituto de Arqueología Lingüística y Folklore "Dr. Pablo Cabrera”. Córdoba: Imprenta de la Universidad Nacional de Córdoba.

Serrano, A. (1958). Manual de la cerámica indígena. Córdoba: Editorial Assandri.

Sprovieri, M. (2014). Variabilidad de los torteros de La Paya y de otros sitios del valle Calchaquí (Salta), y semejanzas interregionales. Comechingonia, 18(1), 117-137.

Taboada, C. (2014). Sequía Vieja y los Bañados de Añatuya en Santiago del Estero. Nodo de desarrollo local e interacción macrorregional. Comechingonia, 18(1), 93-116.

Taboada, C. y Angiorama, C. (2010). Metales, textiles y cerámica. Tres líneas de análisis para pensar una vinculación entre los habitantes de la llanura santiagueńa y el Tawantinsuyu. Memoria Americana, 18(2), 11- 41.

Taboada, C., Angiorama, C., Leiton, D. M. y López Campeny, S. M. L. (2013). En la llanura y en los valles... Relaciones entre las poblaciones de las tierras bajas santiagueñas y el Estado Inca. Intersecciones en Antropología, 14(1), 137-156.

Tissera, L. (2016). Construcción de narrativas en torno a la construcción del arte rupestre de Achalita 1 (sur del Valle de Traslasierra, provincia de Córdoba). En Oliva, F., Rocchietti, A. M. y Solomita, F. (Eds.). Imágenes rupestres, lugares y regiones (pp. 331-342). Rosario: Universidad Nacional de Rosario. 
